\title{
Fuzzy and PI Controller Based SHAF for Mitigation of Current Harmonics with P-Q Method Using Matlab and RTDS Hardware
}

\author{
Suresh Mikkili, Anup Kumar Panda \\ Department of Electrical Engineering, National Institute of Technology, Rourkela, India \\ E-mail: \{msuresh.ee, akpanda.ee\}@gmail.com \\ Received February 28, 2011; revised March 28, 2011; accepted April 2, 2011
}

\begin{abstract}
The main objective of this paper is to develop PI and Fuzzy logic controllers to analyse the performance of instantaneous real active and reactive power (p-q) control strategy for extracting reference currents of shunt active filters under balanced, un-balanced and balanced non-sinusoidal conditions. When the supply voltages are balanced and sinusoidal, then all controllers converge to the same compensation characteristics. However, when the supply voltages are distorted and/or un-balanced sinusoidal, these control strategies result in different degrees of compensation in harmonics. The p-q control strategy with PI controller is unable to yield an adequate solution when source voltages are not ideal. Extensive simulations were carried out; simulations were performed with balance, unbalanced and non sinusoidal conditions. Simulation results validate the dynamic behaviour of Fuzzy logic controller over PI controller. The 3-ph 4-wire SHAF system is also implemented on a Real Time Digital Simulator (RTDS Hardware) to further verify its effectiveness. The detailed simulation and RTDS Hardware results are included.
\end{abstract}

Keywords: Harmonic Compensation Shunt Active Filter (SHAF), P-Q Control Strategy, PI Controller, Fuzzy Controller, RTDS Hardware

\section{Introduction}

Instantaneous active and reactive theory (p-q theory) was introduced by H. Akagi, Kawakawa, and Nabae in 1984 [1]. Since then, many scientists [2-6] and engineers made significant contributions to its modifications in threephase four-wire circuits and its applications to power electronic equipment. The p-q theory [7] based on a set of instantaneous powers defined in the time domain. No restrictions are imposed on the voltage and current waveforms, and it can be applied to three phase systems with or without neutral wire for three phase generic voltage and current waveforms. Thus it is valid not only in the steady state but also in the transient state. $p$-q theory needs additional PLL circuit for synchronization so $\mathrm{p}-\mathrm{q}$ method is frequency variant.

Fuzzy logic controllers [8] have generated a great deal of interest in various applications and have been introduced in the power-electronics. The advantages of fuzzy logic controllers over the conventional PI controller are that they do not need an accurate mathematical model; they can work with imprecise inputs, can handle nonlin- earity, and may be more robust than the conventional PI controller. The Mamdani type of fuzzy controller used for the control of APF gives better results compared with the PI controller, but it has the drawback of a larger number of fuzzy sets and 49 rules [9].

Though several control techniques and strategies [10] had developed but still performance of filter in contradictions, these became primarily motivation for the current paper. Present paper mainly focused on two controllers i.e., fuzzy and PI. Additionally we developed a filter with instantaneous active and reactive power (p-q) method which is prominent one with this we analysed the performance of filter under different main voltages. On observing fuzzy controller shows some superior performance over PI controller. To validate current observations, Extensive simulations were performed and the detailed simulation and RTDS Hardware results are included.

\section{Compensation Principle}

The active power filter is controlled to draw/supply the 
compensating current [11] if from/to the load to cancel out the current harmonics on $\mathrm{AC}$ side and reactive power flow from/to the source there by making the source current in phase with source voltage.

Figure 1 shows the basic compensation principle of the active power filter and it serves as an energy storage element to supply the real power difference between load and source during the transient period. When the load condition changes the real power balance between the mains and the load will be disturbed. This real power difference is to be compensated by the DC capacitor. This changes the DC capacitor voltage away from the reference voltage.

In order to keep satisfactory operation or the active filter, the peak value of the reference source current must be adjusted to proportionally change the real power drawn from the source. This real power charged/discharged by the capacitor compensates the real power difference between the consumed by the load and that of supplied by the source. If the DC capacitor voltage is recovered and attains the reference voltage, the real power supplied by the source is supposed to be equal to that consumed by the load again.

\section{Instantaneous Active and Reactive Power (P-Q) Method}

The control algorithm block diagram for $p-q$ method is depicted in Figure 2. The three-phase source voltages $\left(v_{\mathrm{s} a}, v_{\mathrm{s} b}, v_{\mathrm{s} c}\right)$ and load currents $\left(i_{\mathrm{L} a}, i_{\mathrm{L} b}, i_{\mathrm{L} c}\right)$ in the $a-b-c$ coordinates are algebraically transformed to the $\alpha-\beta$ coordinates using Clarke's transformation.

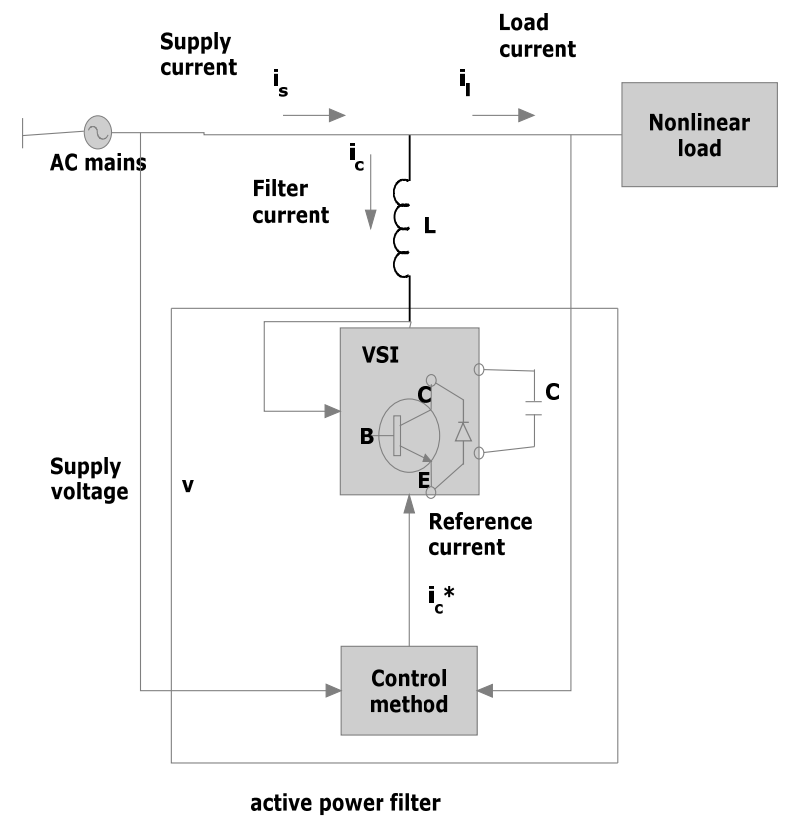

Figure 1. Basic compensation principle.
In this method [12], a set of voltages $\left(v_{a}, v_{b}, v_{c}\right)$ and currents $(i a, i b, i c)$ from phase coordinates are first transferred to the $0 \alpha \beta$ coordinates using Clark transformation:

$$
\begin{aligned}
& {\left[\begin{array}{l}
V_{0} \\
V_{\alpha} \\
V_{\beta}
\end{array}\right]=C\left[\begin{array}{l}
v_{a} \\
v_{b} \\
v_{c}
\end{array}\right] ;\left[\begin{array}{l}
i_{0} \\
i_{\alpha} \\
i_{\beta}
\end{array}\right]=C\left[\begin{array}{l}
i_{L a} \\
i_{L b} \\
i_{L c}
\end{array}\right]} \\
& C=\sqrt{\frac{1}{3}}\left[\begin{array}{ccc}
\frac{1}{\sqrt{2}} & \frac{1}{\sqrt{2}} & \frac{1}{\sqrt{2}} \\
1 & -\frac{1}{2} & -\frac{1}{2} \\
0 & \frac{\sqrt{3}}{2} & -\frac{\sqrt{3}}{2}
\end{array}\right]
\end{aligned}
$$

where $C$ is the so called transformation matrix $\|C\|=1$ and $C^{-1}=C^{T}$

Generalized instantaneous power, $p(t)$

$$
P=\left[\begin{array}{c}
v_{a} \\
v_{b} \\
v_{c}
\end{array}\right] \cdot\left[\begin{array}{ll}
i_{l a} & i_{l b} i_{l c}
\end{array}\right]=v_{a} i_{l a}+v_{b} i_{l b}+v_{c} i_{l c}
$$

The $\mathrm{p}-\mathrm{q}$ formulation defines the generalized instantaneous power, $p(t)$, and instantaneous reactive power vector, $q(t)$ in terms of the $\alpha-\beta-0$ components as

$$
\begin{aligned}
& P=v_{\alpha \beta 0} \cdot i_{\alpha \beta 0}=v_{\alpha} i_{\alpha}+v_{\beta} i_{\beta}+v_{0} i_{0} \\
& q=v_{\alpha \beta 0} \times i_{\alpha \beta 0}=\left[\begin{array}{c}
q_{\alpha} \\
q_{\beta} \\
q_{0}
\end{array}\right]=\left[\begin{array}{cc}
\left|\begin{array}{cc}
v_{0} & v_{\alpha} \\
i_{0} & i_{\alpha}
\end{array}\right| \\
\left|\begin{array}{cc}
v_{\alpha} & v_{\beta} \\
i_{\alpha} & i_{\beta}
\end{array}\right| \\
\mid v_{\beta} & v_{0} \\
i_{\beta} & i_{0}
\end{array} \mid\right] \\
& \text { where } v_{\alpha \beta 0}=\left[\begin{array}{c}
v_{\alpha} \\
v_{\beta} \\
v_{0}
\end{array}\right] ; \quad i_{\alpha \beta 0}=\left[\begin{array}{c}
i_{\alpha} \\
i_{\beta} \\
i_{0}
\end{array}\right] \\
& q=\|\boldsymbol{q}\|=\sqrt{q_{\alpha}^{2}+q_{\beta}^{2}+q_{0}^{2}} \\
& {\left[\begin{array}{c}
p \\
q_{\alpha} \\
q_{\beta} \\
q_{0}
\end{array}\right]=\left[\begin{array}{ccc}
v_{\alpha} & v_{\beta} & v_{0} \\
0 & -v_{0} & v_{\beta} \\
v_{0} & 0 & -v_{\alpha} \\
-v_{\beta} & v_{\alpha} & 0
\end{array}\right]\left[\begin{array}{c}
i_{\alpha} \\
i_{\beta} \\
i_{0}
\end{array}\right]} \\
& {\left[\begin{array}{c}
i_{\alpha} \\
i_{\beta} \\
i_{0}
\end{array}\right]=\frac{1}{2} v_{\alpha \beta 0}\left[\begin{array}{cccc}
v_{\alpha} & 0 & v_{0} & -v_{\beta} \\
v_{\beta} & -v_{0} & 0 & v_{\alpha} \\
v_{0} & v_{\beta} & -v_{\alpha} & 0
\end{array}\right]\left[\begin{array}{c}
p \\
q_{\alpha} \\
q_{\beta} \\
q_{0}
\end{array}\right]}
\end{aligned}
$$




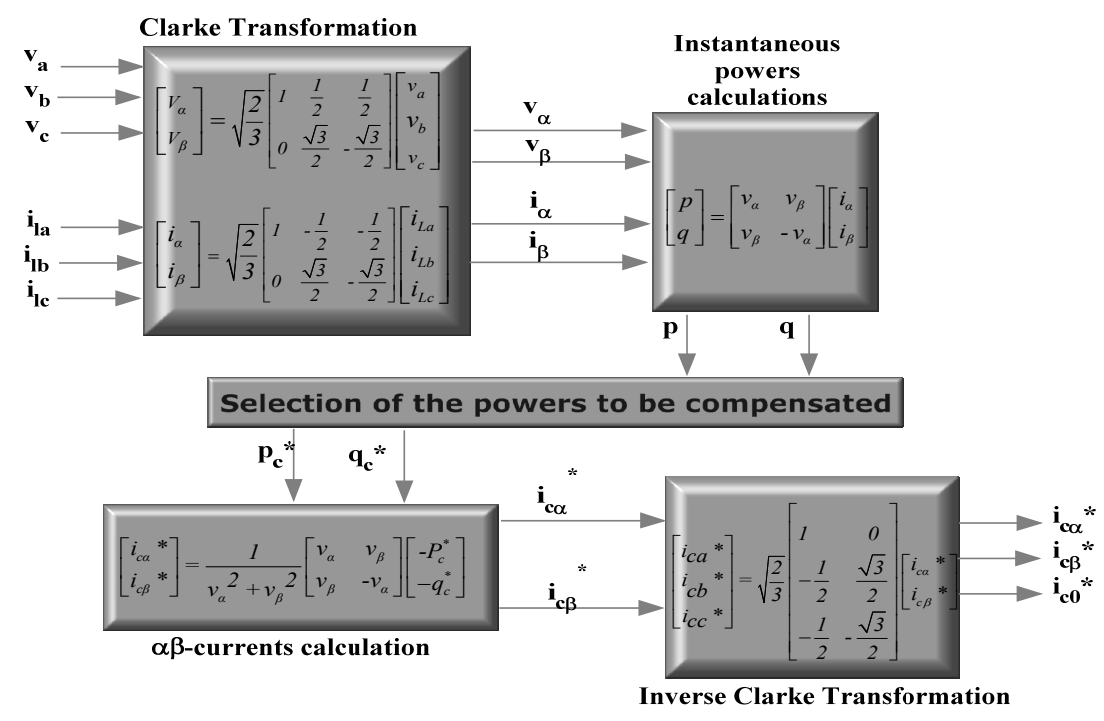

Figure 2. Control method for Shunt current compensation based on p-q theory.

where $v_{\alpha \beta 0}^{2}=v_{\alpha}^{2}+v_{\beta}^{2}+v_{0}^{2}$. In the new coordinates system, the instantaneous power has two components: the zero-sequence instantaneous real power, $P_{0}$, and the instantaneous real power due to positive and negative sequence components, $P_{\alpha \beta}$

$$
\begin{gathered}
P(t)=P_{0}(t)+P_{\alpha \beta}(t) \\
P_{0}(t)=v_{0} i_{0} \\
P_{\alpha \beta}(t)=\left[\begin{array}{c}
v_{\alpha} \\
v_{\beta}
\end{array}\right]\left[i_{\alpha} i_{\beta}\right]=v_{\alpha} i_{\alpha}+v_{\beta} i_{\beta}
\end{gathered}
$$

Using the above equations and considering the orthogonal nature of vectors $\bar{v}$ and $\bar{q}(\bar{v} \cdot \bar{q}=0)$ the reference source current in the $\alpha \beta 0$ frame is

$$
\left[\begin{array}{c}
i_{s \alpha} \\
i_{s \beta} \\
i_{s 0}
\end{array}\right]=\frac{1}{2}\left[\begin{array}{cccc}
v_{\alpha} & 0 & v_{0} & -v_{\beta} \\
v_{\alpha \beta 0} & -v_{0} & 0 & v_{\alpha} \\
v_{0} & v_{\beta} & -v_{\alpha} & 0
\end{array}\right]\left[\begin{array}{c}
p \\
q_{\alpha} \\
q_{\beta} \\
q_{0}
\end{array}\right]
$$

The objective of the p-q strategy is to get the source to give only the constant active power demanded by the load $P_{s}(t)=P_{L 0}(t)+P_{L \alpha \beta}(t)$

In addition, the source must deliver no zero-sequence active power $i_{s 0 r e f}=0$ (so that the zero-sequence component of the voltage at the PCC does not contribute to the source power). The reference source current in the $\alpha-\beta$-0frame is therefore

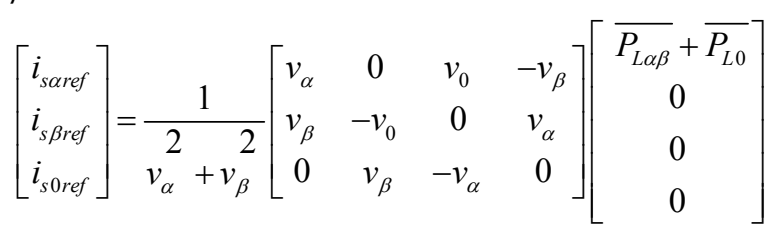

$$
\left[\begin{array}{l}
i_{\text {saref }} \\
i_{s \beta r e f} \\
i_{\text {soref }}
\end{array}\right]=\frac{\overline{P_{L \alpha \beta}}+\overline{P_{L 0}}}{v_{\alpha}^{2}+v_{\beta}^{2}}\left[\begin{array}{l}
v_{\alpha} \\
v_{\beta} \\
0
\end{array}\right]
$$

\section{Construction of PI Controller}

Figures $\mathbf{3}$ and $\mathbf{4}$ show the internal structure of the control circuit. The control scheme consists of PI controller, limiter, and three phase sine wave generator for reference current generation and generation of switching signals. The peak value of reference currents is estimated by regulating the DC link voltage. The actual capacitor voltage is compared with a set reference value [13].

The error signal is then processed through a PI controller, which contributes to zero steady error in tracking the reference current signal. The output of the PI controller is considered as peak value of the supply current $\left(I_{\max }\right)$, which is composed of two components: 1) fundamental active power component of load current, and 2) loss component of APF; to maintain the average capacitor voltage to a constant value. Peak value of the current $\left(I_{\max }\right)$ so obtained, is multiplied by the unit sine vectors in phase with the respective source voltages to obtain the reference compensating currents. These estimated reference currents $\left(I_{s a}{ }^{*}, I_{s b}{ }^{*}, I_{s c}{ }^{*}\right)$ and sensed actual currents (Isa, Is $b, I s c)$ are compared at a hysteresis band, which gives the error signal for the modulation technique. This error signal decides the operation of the converter switches. In this current control circuit configuration, the source/supply currents $I_{s a b c}$ are made to follow the sinusoidal reference current $I_{a b c}$, within a fixed hysteretic band. The width of hysteresis window determines the source current pattern, its harmonic spectrum and the 


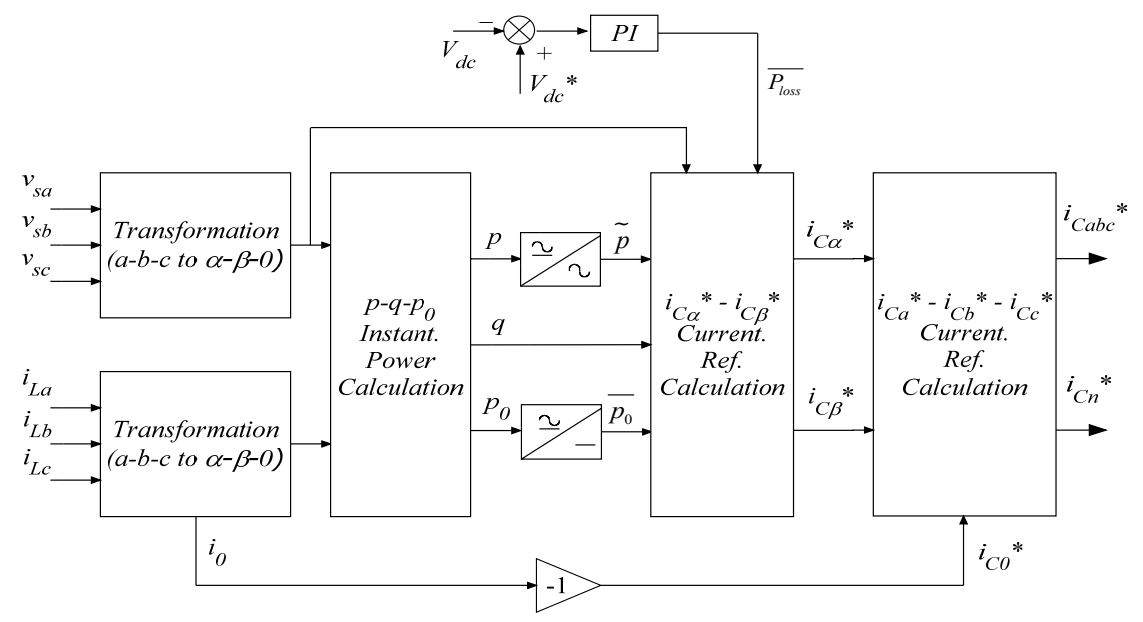

Figure 3. Reference current extraction with conventional p-q method with PI controller.

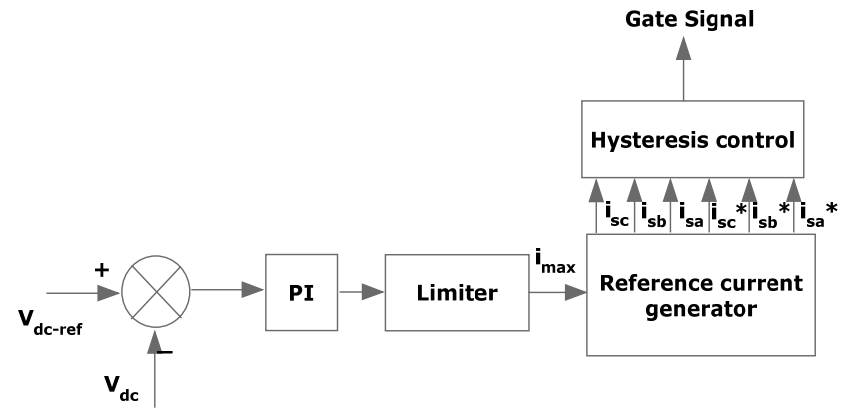

Figure 4. Conventional PI controller.

switching frequency of the devices.

The DC link capacitor voltage is kept constant throughout the operating range of the converter. In this scheme, each phase of the converter is controlled independently. To increase the current of a particular phase, the lower switch of the converter associated with that particular phase is turned on while to decrease the current the upper switch of the respective converter phase is turned on. With this one can realize, potential and feasibility of PI controller.

\section{Construction of Fuzzy Logic Controller}

Figure 5 shows the internal structure of the control circuit. The control scheme consists of Fuzzy controller [14], limiter, and three phase sine wave generator for reference current generation and generation of switching signals. The peak value of reference currents is estimated by regulating the DC link voltage. The actual capacitor voltage is compared with a set reference value. The error signal is then processed through a Fuzzy controller, which contributes to zero steady error in tracking the reference current signal.

A fuzzy controller converts a linguistic control strat- egy into an automatic control strategy, and fuzzy rules are constructed by expert experience or knowledge database [15]. Firstly, input Error $E$ and change in Error have been placed of the angular velocity to be the input variables of the fuzzy logic controller. Then the output variable of the fuzzy logic controller is presented by the control Current $I_{\max }$. To convert these numerical variables into linguistic variables, the following seven fuzzy levels or sets are chosen as: NB (negative big), NM (negative medium), NS (negative small), ZE (zero), PS (positive small), PM (positive medium), and PB (positive big) as shown in Figure 6.

Table 1. Rule base.

\begin{tabular}{llllllll}
\hline (de/dt)/e & NB & NM & NS & Z & PS & PM & PB \\
\hline NB & NB & NB & NB & NB & NM & NS & Z \\
NM & NB & NB & NB & NM & NS & Z & PS \\
NS & NB & NB & NM & NS & Z & PS & PM \\
Z & NB & NM & NS & Z & PS & PM & PB \\
PS & NM & NS & Z & PS & PM & PB & PB \\
PM & NS & Z & PS & PM & PB & PB & PB \\
PB & Z & PS & PM & PB & PB & PB & PB \\
\hline
\end{tabular}




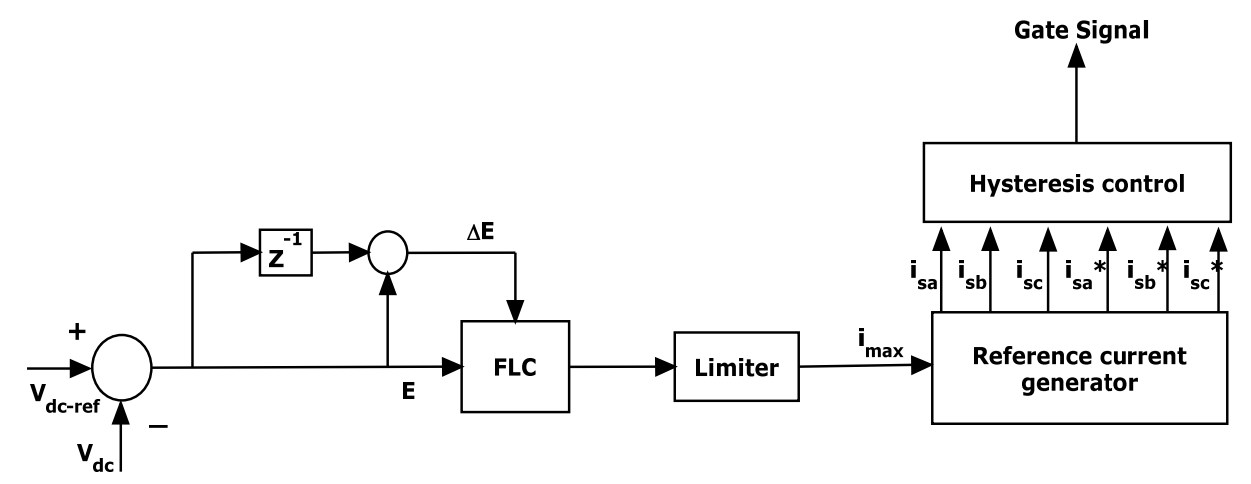

Figure 5. Proposed fuzzy inference system.

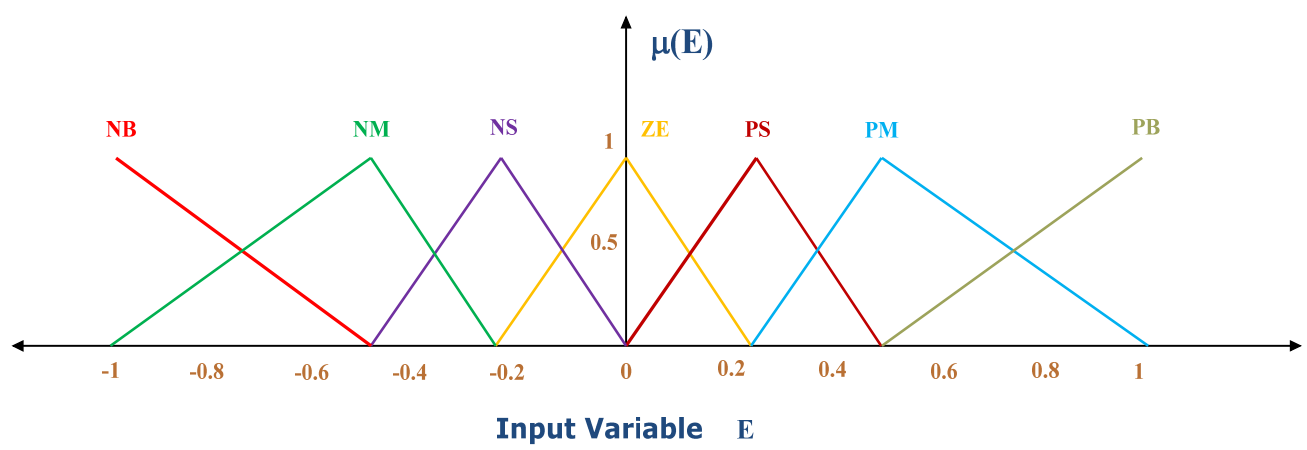

(a)

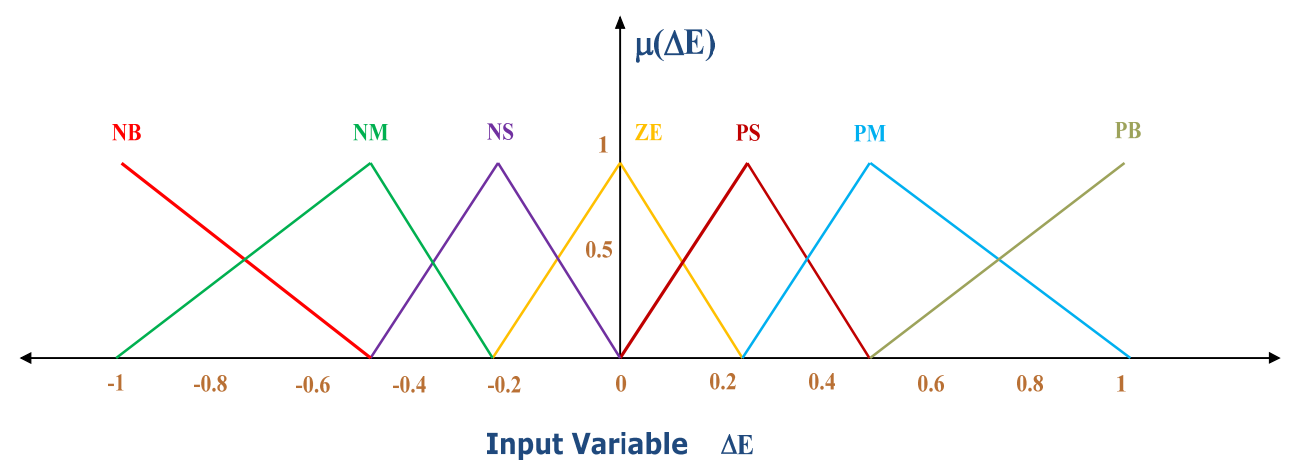

(b)

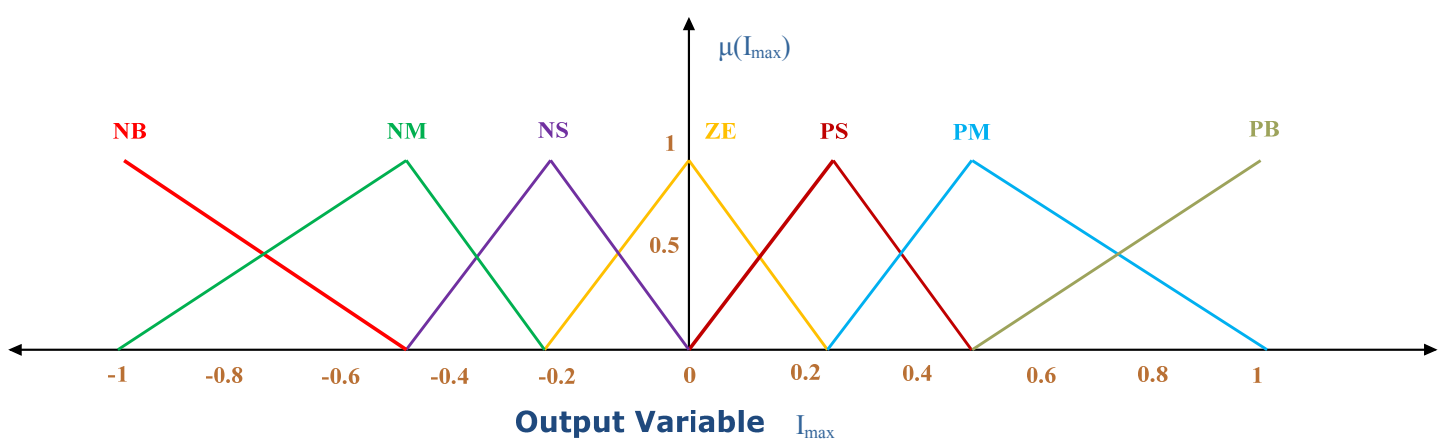

(c)

Figure 6. (a) Input variable “ $E$ ” membership function. (b) Input change in error normalized MF. (c) Output $I_{\max }$ normalized MF. 
The fuzzy controller is characterized as follows:

1) Seven fuzzy sets for each input and output.

2) Fuzzification using continuous universe of discourse.

3) Implication using Mamdani’s "min" operator.

4) De-fuzzification using the "centroid" method.

The bock diagram of Fuzzy logic controller is shown in Figure 7. It consists of blocks

- Fuzzification Interface.

- Knowledge base.

- Decision making logic.

- Defuzzification.

\section{RTDS Hardware}

This simulator was developed with the aim of meeting the transient simulation needs of electromechanical drives and electric systems while solving the limitations of traditional real-time simulators which is shown in Figure 8. It is based on a central principle: the use of widely available, user-friendly, highly competitive commercial products (PC platform, Simulink ${ }^{\mathrm{TM}}$ ). The real-time simulator [16] consists of two main tools: a real-time distributed simulation package (RT-LAB) for the execution of Simulink block diagrams on a PC-cluster, and algorithmic toolboxes designed for the fixed-time-step simulation of stiff electric circuits and their controllers. Realtime simulation and Hardware-In-the-Loop (HIL) applications are increasingly recognized as essential tools for engineering design and especially in power electronics and electrical systems.

\subsection{Simulator Architecture}

\subsubsection{Block Diagram and Schematic Interface}

The present real-time electric simulator is based on RT LAB real-time, distributed simulation platform; it is optimized to run Simulink in real-time, with efficient fixedstep solvers, on PC Cluster. Based on COTS non-proprietary PC components, RT LAB [17] is a modular real-time simulation platform, for the automatic implementation of system-level, block diagram models, on standard PC's. It uses the popular MATLAB/Simulink as a front-end for editing and viewing graphic models in block-diagram format. The block diagram models become the source from which code can be automatically generated, manipulated and downloaded onto target processors (Pentium and Pentium-compatible) for real-time or distributed simulation.

\subsubsection{Simulator Configuration}

In a typical configuration (Figure 9), the RT-LAB simulator consists of

- One or more target PC's (computation nodes); one of the PCs (Master) manages the communication between the hosts and the targets and the communication between all other target PC's. The targets use the REDHAT real-time operating system.

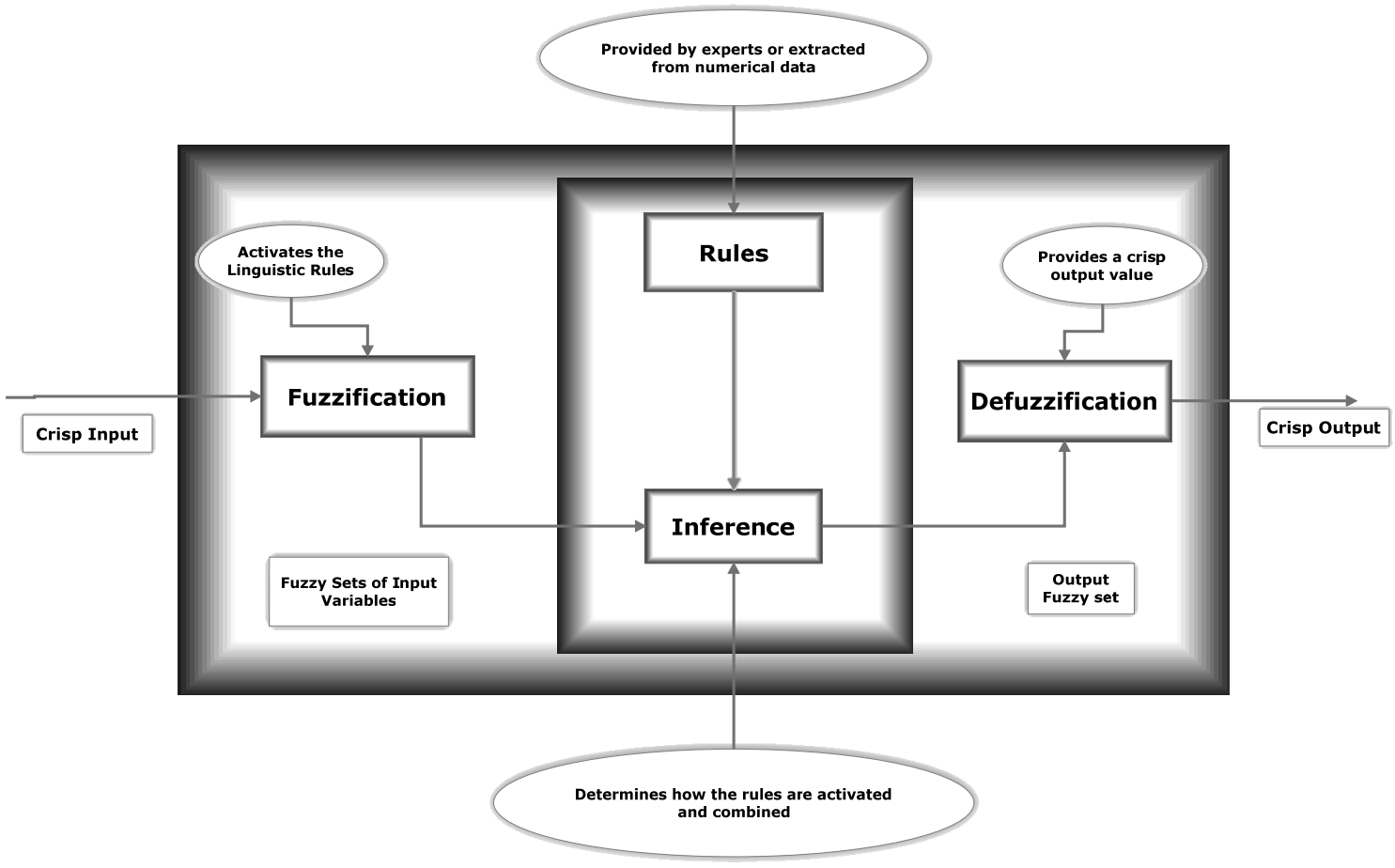

Figure 7. Block diagram of fuzzy logic controller (FLC). 


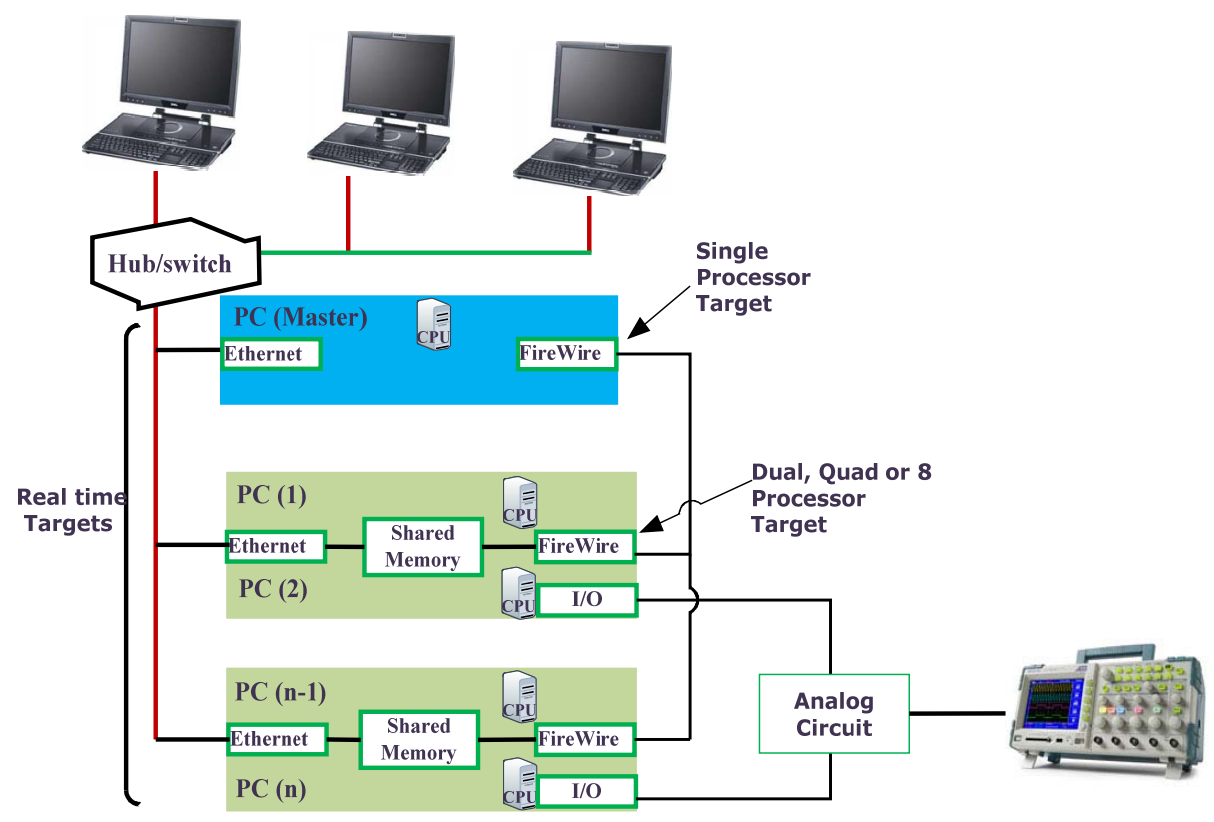

Figure 8. RT-LAB simulator architecture.

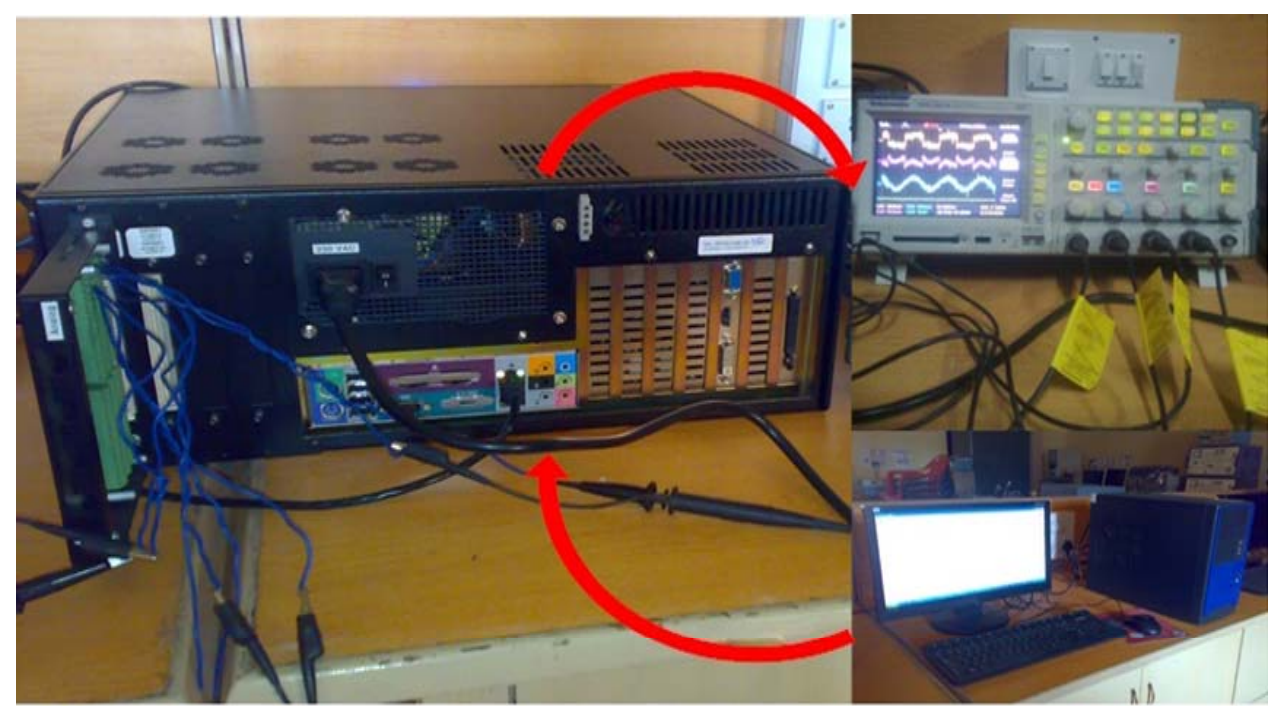

Figure 9. RTDS hardware.

- One or more host PC's allowing multiple users to access the targets; one of the hosts has the full control of the simulator, while other hosts, in read-only mode, can receive and display signals from the real-time simulator.

- I/O's of various types (analog in and out, digital in and out, PWM in and out, timers, encoders, etc.). I/O's can be managed by dedicated processors distributed over several nodes.

\section{Simulation and RTDS Results}

Figures 10-12 illustrates the performance of shunt active power filter under different main voltages, as load is highly inductive, current draw by load is integrated with rich harmonics.

Figure 10 illustrates the performance of Shunt active power filter under balanced sinusoidal voltage condition, THD for $\mathrm{p}-\mathrm{q}$ method with PI Controller using Matlab simulation is $2.15 \%$ and using RTDS Hard ware is 2.21\%; THD for p-q method with Fuzzy Controller using Matlab simulation is $1.27 \%$ and using RTDS Hard ware is $1.45 \%$.

Figure 11 illustrates the performance of Shunt active power filter under un-balanced sinusoidal voltage condition, THD for $\mathrm{p}-\mathrm{q}$ method with PI Controller using Matlab 
3 ph 4w Bal Sin p-q with PI Controller (MATLAB Simulation)
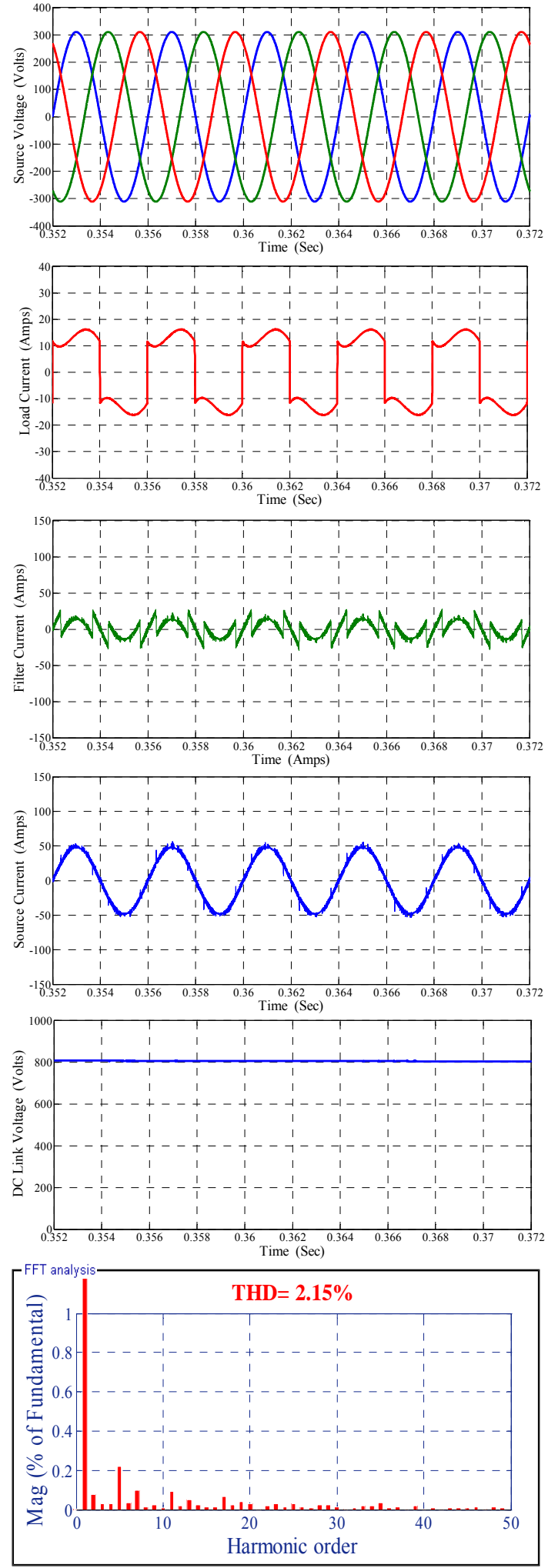

(a)
3 ph 4w Bal Sin p-q with PI Controller (RT DS Hardware)
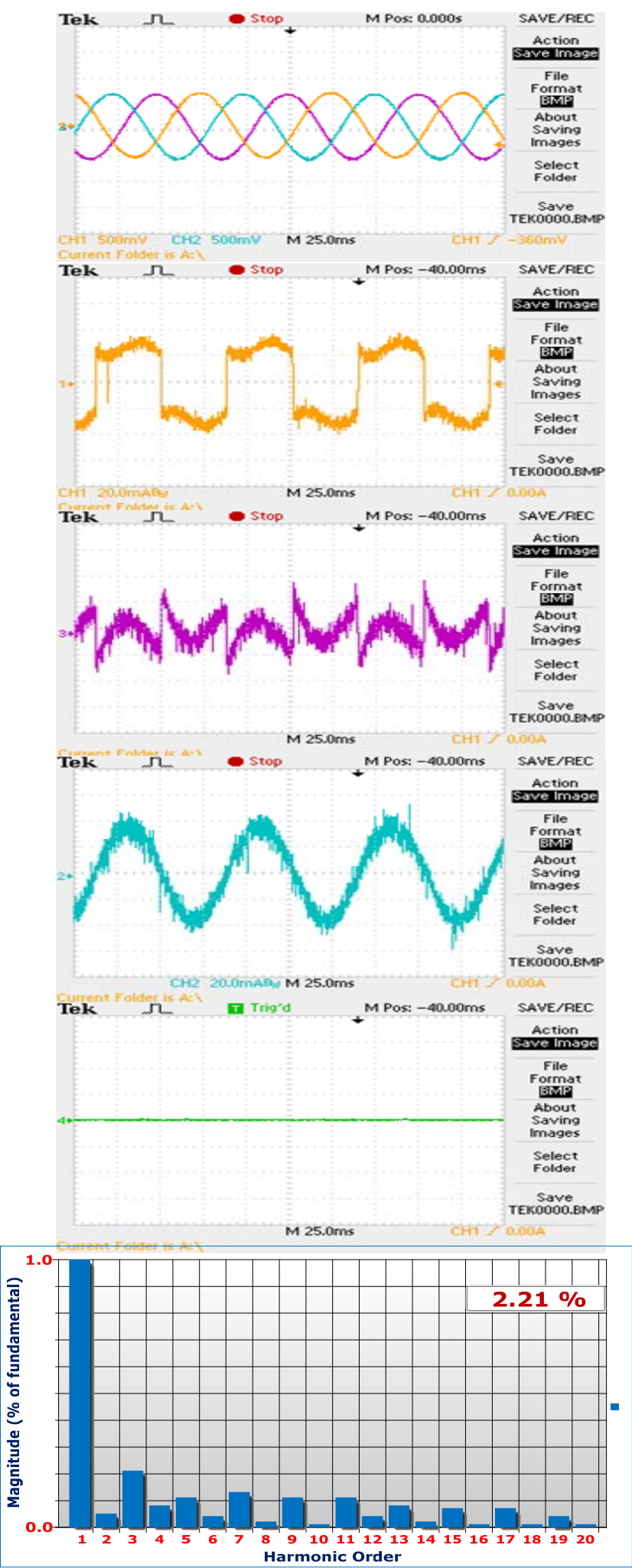

(b) 
3ph 4w Bal Sin p-q with Fuzzy Controller (MATLAB Simulation)
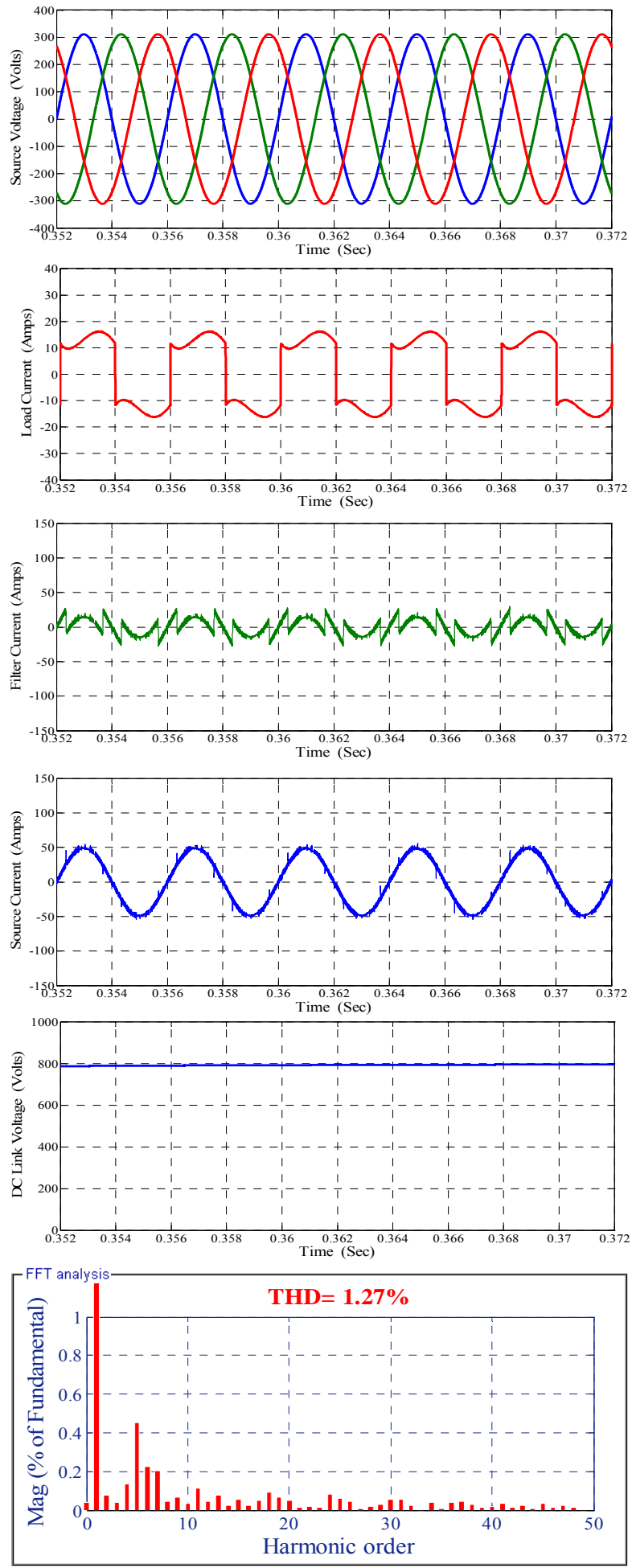

(c) 3ph 4w Bal Sin p-q with Fuzzy Controller (RTDS Hardware)

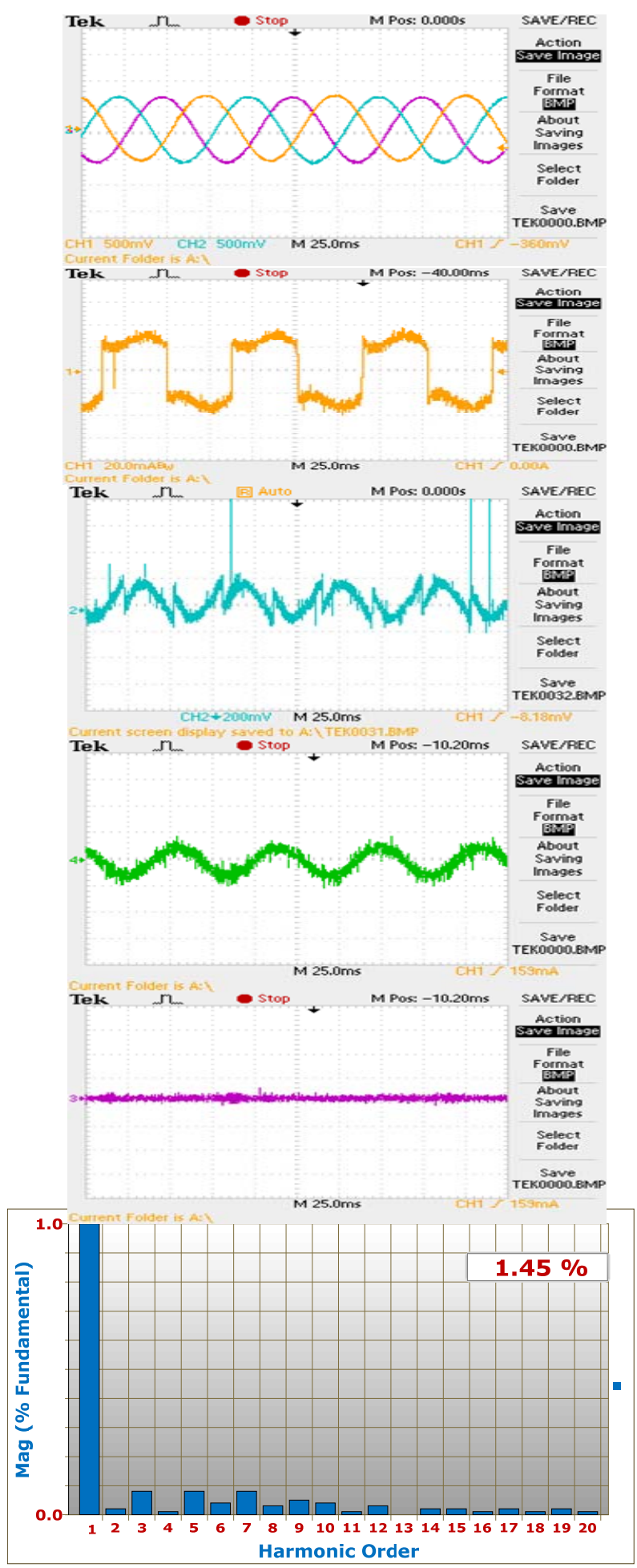

(d)

Figure 10. 3ph 4wire shunt ative filter response with p-q control strategy under balanced sinusoidal using. (a) PI with matlab; (b) PI with RTDS hardware; (c) Fuzzy with matlab; (d) Fuzzy with RTDS hardware. 
3ph 4w Un-bal Sin p-q with PI Controller

(MATLAB Simulation)
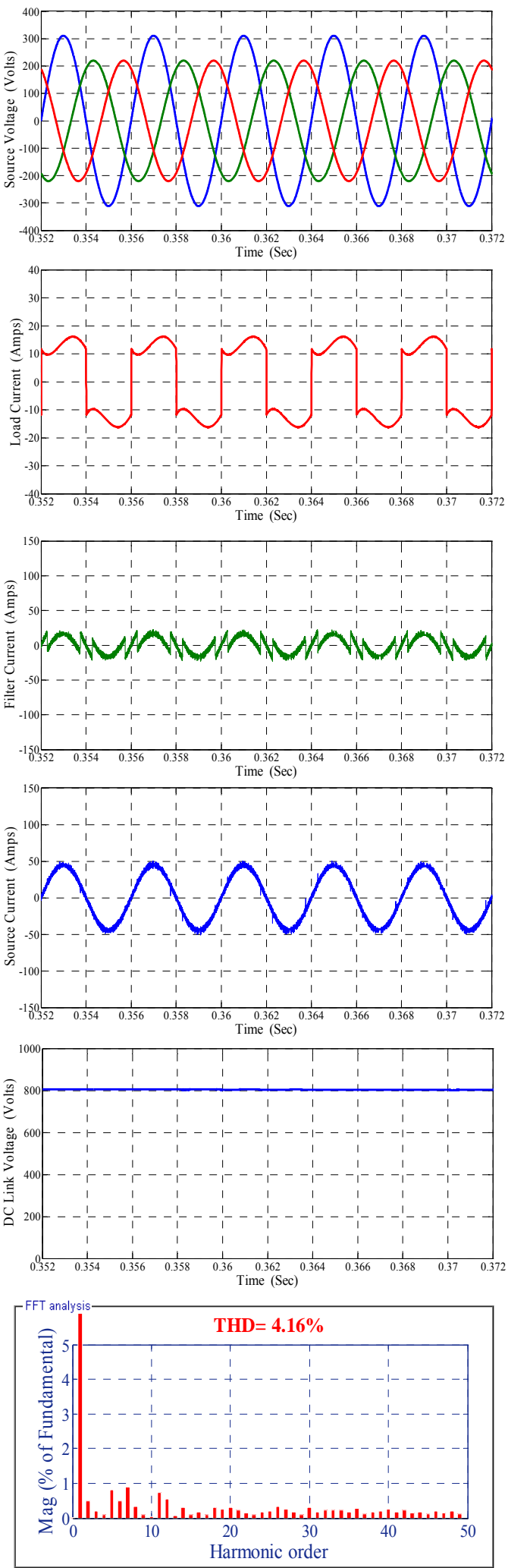

(a)
3 ph 4w Un-bal Sin p-q with PI Controller (RT DS Hardware)

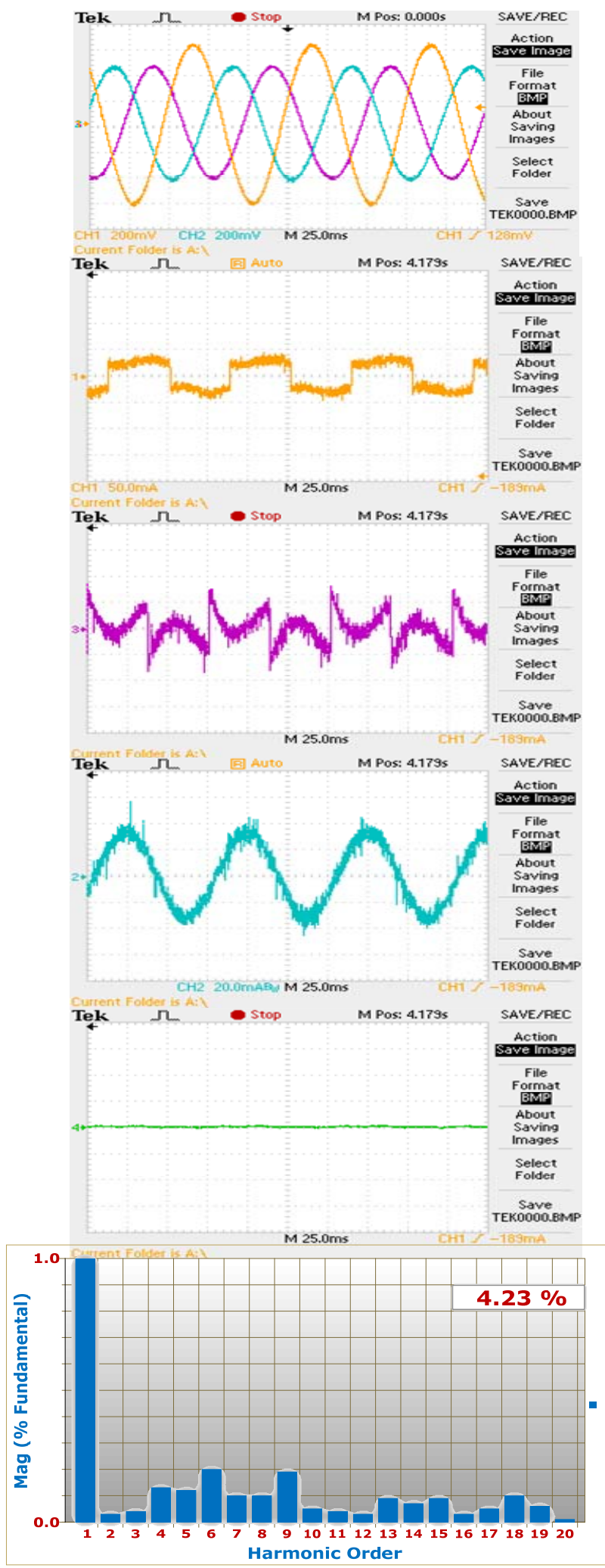

(b) 
3ph 4w Un-bal Sin p-q with Fuzzy Controller (MATLAB Simulation)
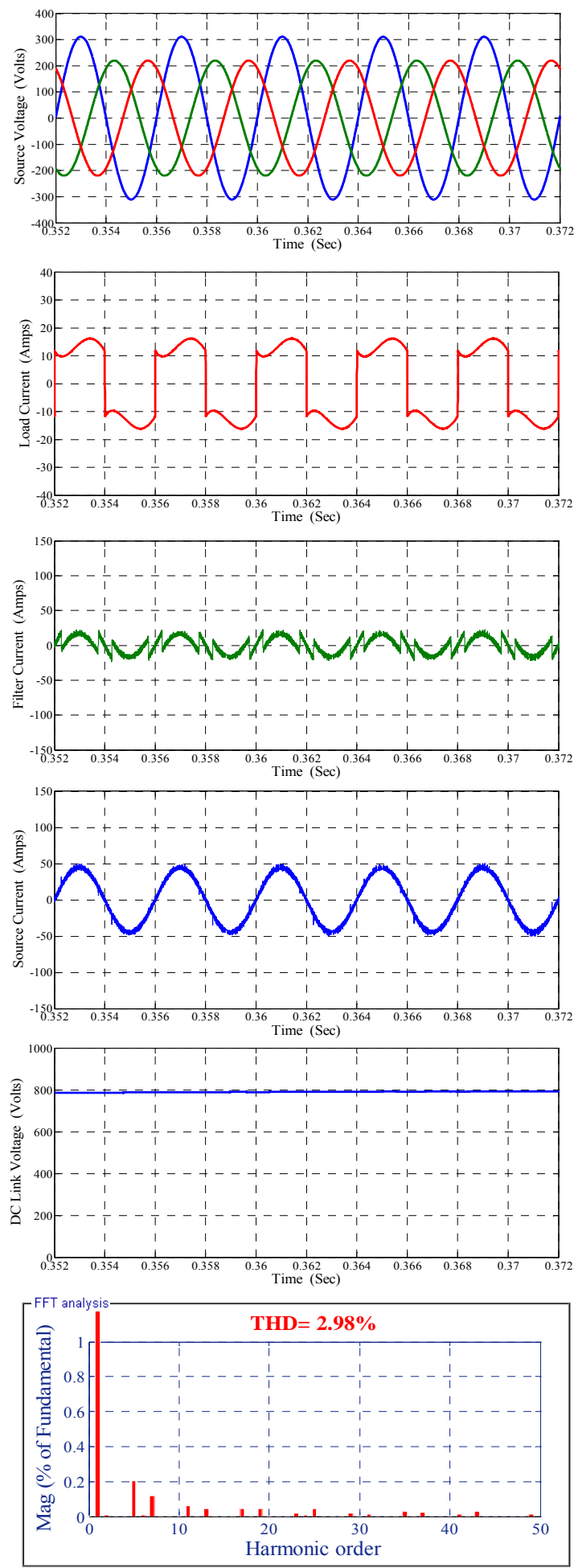

(c)
3 ph 4w Un-bal Sin p-q with Fuzzy Controller (RT DS Hardware)
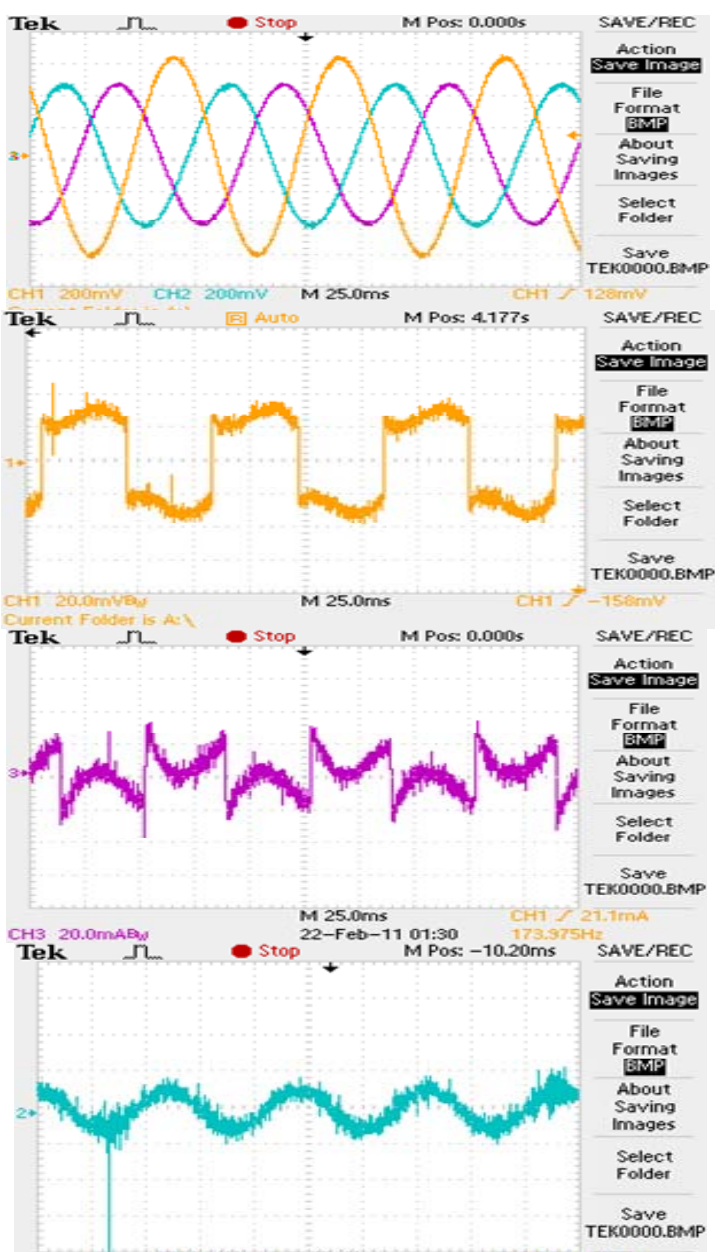

CH2 50.0̈Á M25.0ms
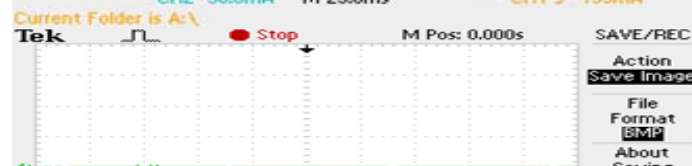

Saving

Select
Folder

Save

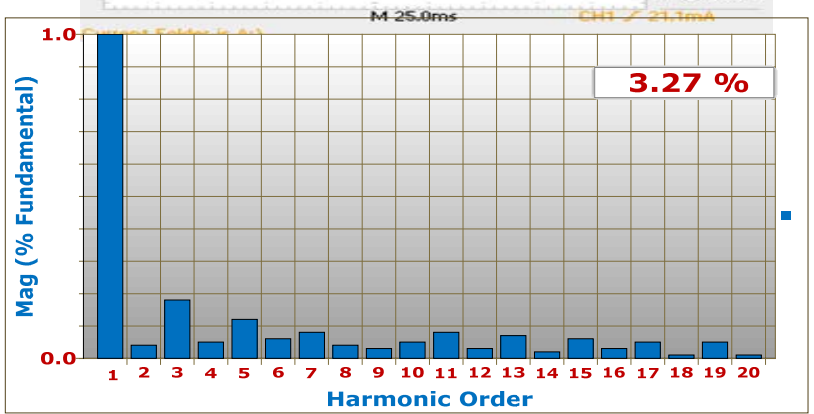

(d)

Figure 11. 3-ph 4wire shunt ative filter response with p-q control strategy under un-balanced sinusoidal using. (a) PI with Matlab; (b) PI with RTDS hardware; (c) Fuzzy with matlab; (d) Fuzzy with RTDS hardware. 
3 ph 4w Non-Sin p-q with PI Controller (MATLAB Simulation)
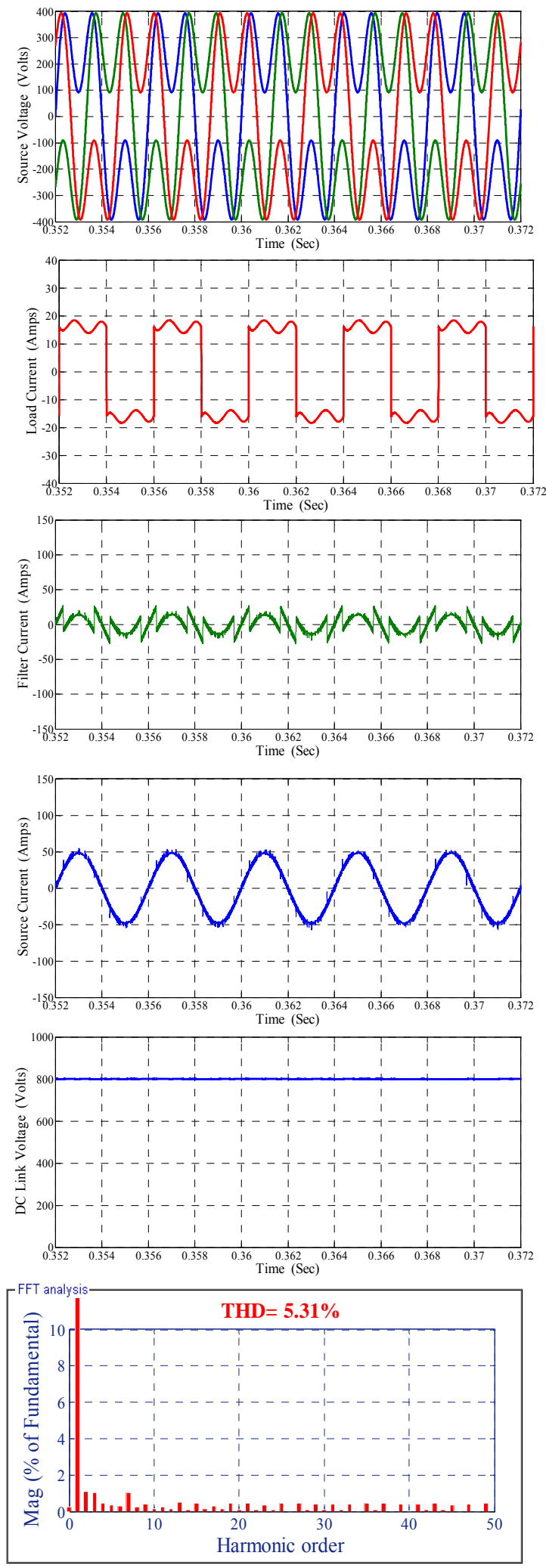

(a)
3 ph 4w Non-Sin p-q with PI Controller (RT DS Hardware)
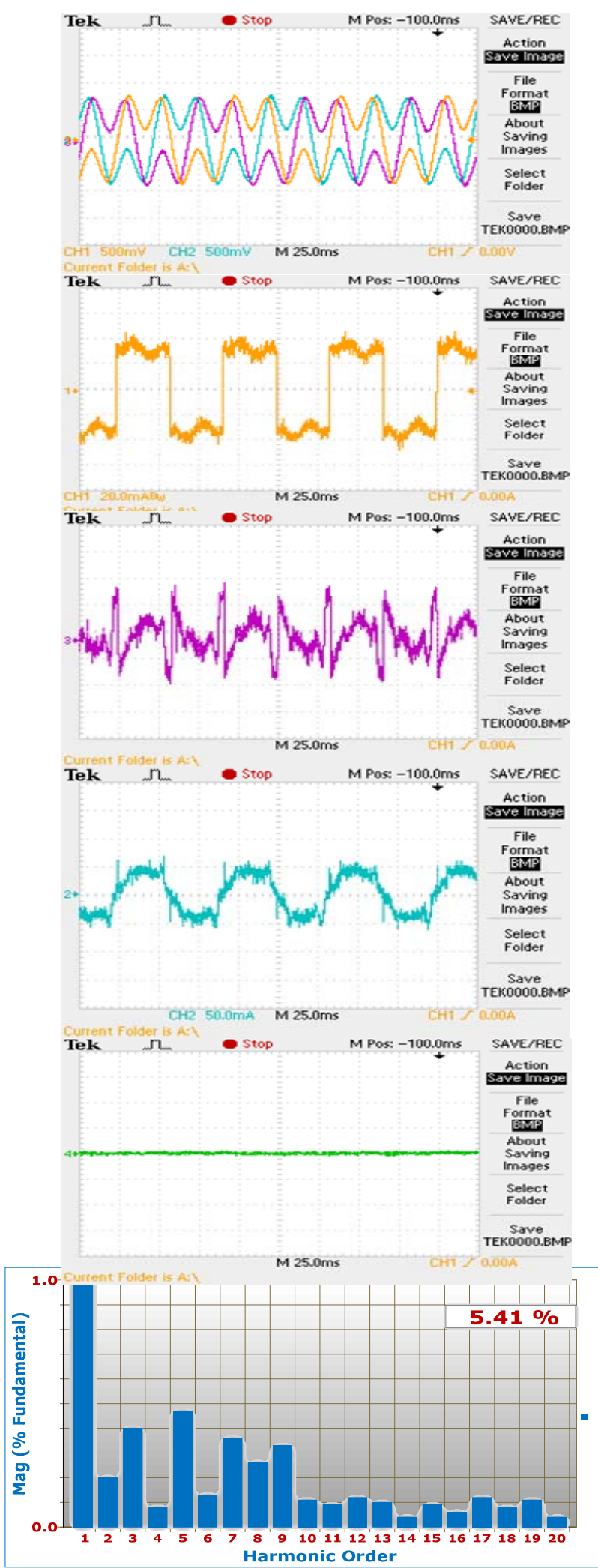

(b) 
$3 p h 4 w$ Non-Sin p-q with Fuzzy Controller (MATLAB Simulation)
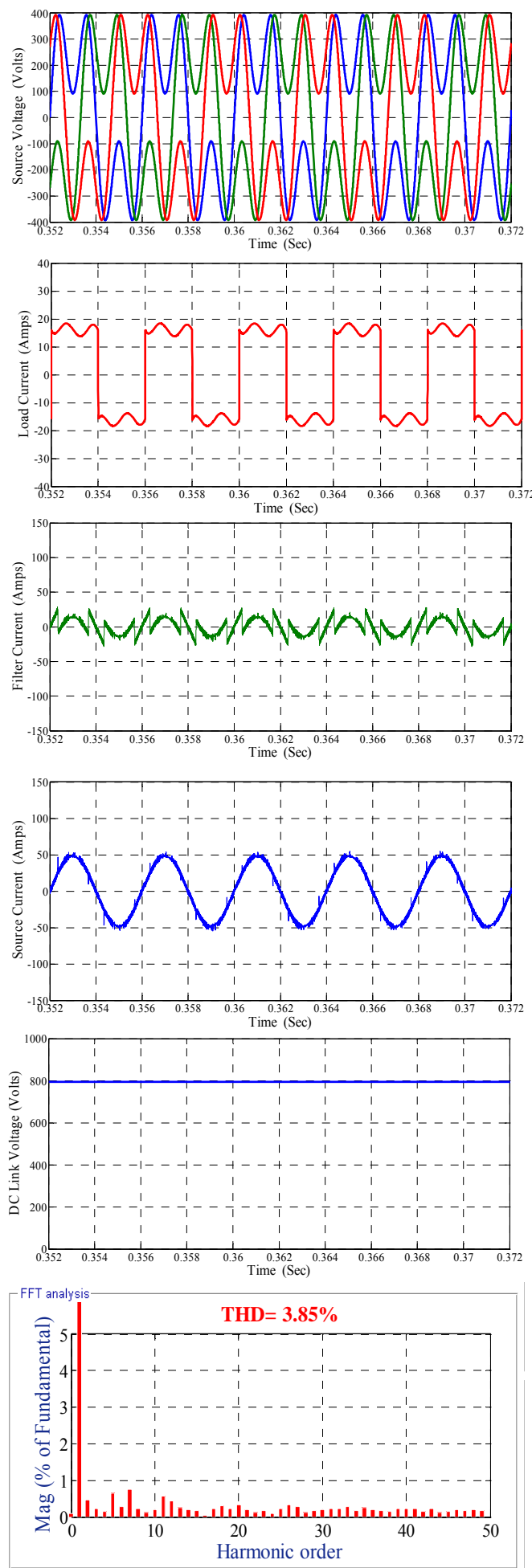

(c) 3ph 4w Non-Sin p-q with Fuzzy Controller (RT DS Hardware)
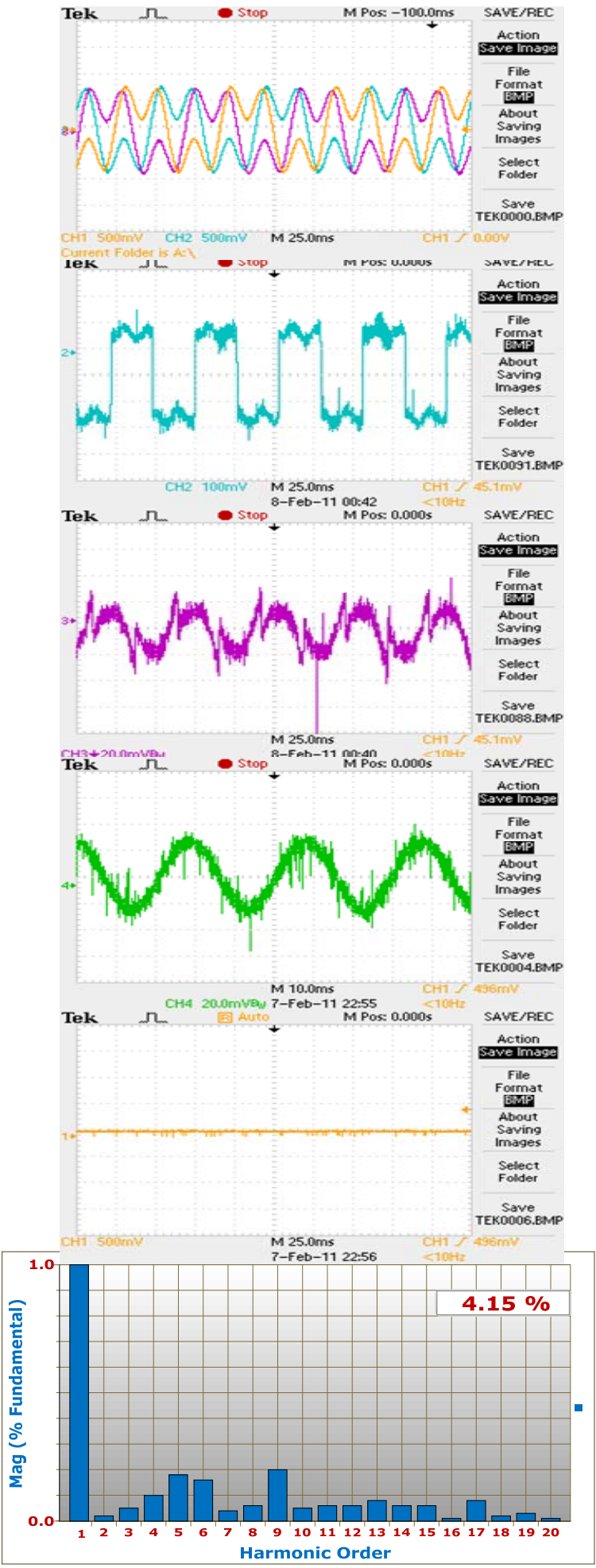

(d)

Figure 12. 3ph 4wire Shunt ative filter response with p-q control strategy under Non-Sinusoidal using. (a) PI with matlab; (b) PI with RTDS hardware; (c) Fuzzy with matlab; (b) Fuzzy with RTDS hardware. 


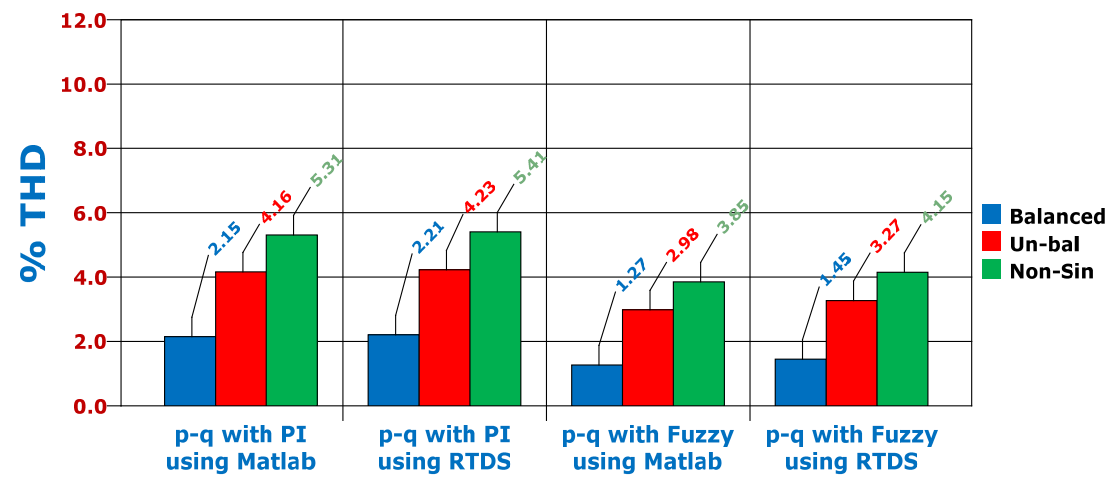

Figure 13. THD for $p-q$ control strategy with PI and fuzzy controllers using Matlab and RTDS hardware.

simulation is $4.16 \%$ and using RTDS Hard ware is $4.23 \%$; THD for $p-q$ method with Fuzzy Controller using matlab simulation is $2.98 \%$ and using RTDS Hard ware is $3.27 \%$.

Figure 12 illustrates the performance of Shunt active power filter under balanced non-sinusoidal voltage condition, THD for $\mathrm{p}-\mathrm{q}$ method with PI Controller using Matlab simulation is $5.31 \%$ and using RTDS Hard ware is $5.41 \%$; THD for p-q method with Fuzzy Controller using Matlab simulation is $3.85 \%$ and using RTDS Hard ware is $4.15 \%$.

\section{Conclusions}

In the present paper two controllers are developed and verified with three phase four wire system. Even though two controllers are capable to compensate current harmonics in the 3-phase 4-wire system, but it is observed that Fuzzy Logic controller shows some dynamic performance over Conventional PI controller. PWM pattern generation based on carrier less hysteresis based current control is used for quick response. Additionally, on contrast of different control strategies; p-q control strategy is used for obtaining reference currents in the system, because in this strategy, angle " $\theta$ " is calculated directly from main voltages and enables operation to be frequency independent their by technique avoids large numbers of synchronization problems. It is also observed that DC voltage regulation system valid to be a stable and steady-state error free system was obtained. Thus with fuzzy logic and p-q approach a novel shunt active filter can be developed. The 3-ph 4-wire SHAF system is also implemented on a Real Time Digital Simulator (RTDS Hardware) to further verify its effectiveness. Essential simulation and RTDS Hardware results are presented to validate the performance of shunt active filter.

\section{References}

[1] H. Akagi, H. Kanazawa and Y. Nabae, "Instantaneous
Reactive Power Compensators Comprising Switching Devices without Energy Storage Components," IEEE Transactions on Industry Applications, Vol. 20, No. 3, 1984, pp. 625-630.

[2] Z. Peng et al., "Harmonic and Reactive Power Compensation Based on the Generalized Instantaneous Reactive Power Theory for Three-Phase Four-Wire Systems," IEEE Transactions on Power Electronics, Vol. 13, No. 5, 1998, pp. 1174-1181.

[3] M. I. M. Montero, et al., "Comparison of Control Strategies for Shunt Active Power Filters in Three-Phase Four-Wire Systems," IEEE Transactions on Power Electronics, Vol. 22, No. 1. 2007, pp. 229-236.

[4] L. Gyugyi and E. C. Strycula, "Active AC Power Filters," IEEE IIAS Annual Meeting, 1976, pp. 529-535.

[5] O. Vodyakho and C. Chris Mi Senior, "Three-Level Inverter-Based Shunt Active Power Filter in Three-Phase Three-Wire and Four-Wire Systems," IEEE Transactions on Power Electronics, Vol. 24, No. 5, 2009, pp. 13501363.

[6] M. Aredes, et al., "Three-Phase Four-Wire Shunt Active Filter Control Strategies," IEEE Transactions on Power Electronics, Vol. 12, No. 2, 1997, pp. 311-318.

[7] H. Akagi, et al., "Instantaneous Power Theory and Applications to Power Conditioning," IEEE Press/Wiley-InterScience 2007, Wiley Online, 2007.

[8] S. Mikkili and A. K. Panda, "Instantaneous Active and Reactive Power and Current Strategies for Current Harmonics Cancellation in 3-ph 4Wire SHAF with Both PI and Fuzzy Controllers," Journal of Energy and Power Engineering, Vol.3, No.3, 2011, pp. 285-298.

[9] M. Suresh, A. K. Panda and Y. Suresh, "Fuzzy Controller Based 3Phase 4Wire Shunt Active Filter for Mitigation of Current Harmonics with Combined p-q and $\mathrm{I}_{\mathrm{d}}-\mathrm{I}_{\mathrm{q}}$ Control Strategies," Journal of Energy and Power Engineering, Vol. 3, No.1, 2011, pp. 43-52.

[10] P. Salmeron and R. S. Herrera, "Distorted and Unbalanced Systems Compensation within Instantaneous Reactive Power Framework," IEEE Transactions on Power Delivery, Vol. 21, No. 3, 2006, pp. 1655-1662.

[11] P. Rodriguez, et al., "Current Harmonics Cancellation in Three-Phase Four-Wire Systems by Using a Four-Branch Star Filtering Topology," IEEE Transactions on Power 
Electronics, Vol. 24, No. 8, 2009, pp. 1939-1950.

[12] S. Mikkili and A. K. Panda, "SHAF for Mitigation of Current Harmonics Using p-q Method with PI and Fuzzy Controllers," Engineering, Technology \& Applied Science Research, Vol. 1, No. 4, 2011, pp. 98-104.

[13] H. Akagi, "New Trends in Active Filters for Power Conditioning," IEEE Transactions on Industry Applications, Vol. 32, No. 6, 1996, pp. 1312-1322.

[14] P. Kirawanich and R. M. O'Connell, "Fuzzy Logic Control of an Active Power Line Conditioner," IEEE Transactions on Power Electronics, Vol. 19, No. 6, 2004, pp. 1574-1585.

[15] S. K. Jain, et al., "Fuzzy Logic Controlled Shunt Active
Power Filter for Power Quality Improvement," IEEE Proceedings Electric Power Applications, Vol. 149, No. 5, 2002, pp. 317-328.

[16] S. Mikkili and A. K. Panda, "RTDS Hardware Implementation and Simulation of 3-ph 4-Wire SHAF for Mitigation of Current Harmonics with p-q and Id-Iq Control Strategies Using Fuzzy Logic Controller," International Journal of Emerging Electric Power Systems, be press Vol. 12, No. 5, 2011, pp. 1-24.

[17] P. Forsyth, et al., "Real Time Digital Simulation for Control and Protection System Testing," IEEE Proceedings Power Electronics Specialists Conference, Santa Fe, Vol. 1, 20-25 June 2004, pp. 329-335. 